\title{
sciendo
}

\section{ANNUAL REPORT ON THE EVALUATION OF PATIENT SATISFACTION AT A PNEUMOPHTHISIOLOGY HOSPITAL}

\author{
VIOLETA FRÂNCU ${ }^{1}$ \\ l "Lucian Blaga” University of Sibiu
}

\begin{abstract}
Keywords: hospitalized Abstract: Patients realize how care was provided, but it is difficult for them to know when patients, quality of expectations were reasonable or when unwanted outcomes were caused by inadequate care or special medical services, degree circumstances. Research in the field shows that satisfaction is related to the perception of technical of satisfaction skills, intelligence and qualification of medical staff, but, in general, the perception of interpersonal communication skills of medical staff is more important. A number of studies have shown that patients tend to be more satisfied with the care provided if the behaviour of the service provider (doctor, nurse, etc.) "conforms" their expectations. Communication skills, empathy, the care offered, attention to personal issues influences how a patient will evaluate the care received.(1,2,3)
\end{abstract}

\section{INTRODUCTION}

When we talk about a high-performance medical system, we are talking about an excellent experience for patients. Therefore, the level of satisfaction of those who cross the threshold of the hospital is not only an indicator of the quality of services provided, but also of success. But how can we measure patient satisfaction to find out where we stand and what we can do exactly? $(4,5)$

First, patient satisfaction is an assessment, the totality of his feelings about the experiences he had after consuming medical services. Patient satisfaction is not only essential to maintain a competitive level of performance, but also to find solutions to improve medical processes and practice. Patient satisfaction influences his clinical outcomes and last but not least, his relationship with the service provider. $(6,7,8)$

A satisfied patient will confidently return to the doctor or hospital, increasing addressability. Patient satisfaction assessment is a tool for measuring how the medical unit meets patients' values and expectations. $(9,10)$

\section{AIM}

The purpose of this study is to assess the degree of satisfaction of inpatients regarding the hospital accommodation conditions and the quality of medical services provided. The monthly evaluation of the results of the questionnaires can identify the main dissatisfaction of patients, which seeks the best solutions and the most appropriate measures to increase the quality of medical services, reducing risks and increasing the safety of inpatients.

Objectives of the study:

assessing the opinion of patients on the degree of satisfaction during hospitalization;

identifying the main existing problems;

finding solutions to improve the identified problems; improving the quality management in the medical departments of the hospital by applying a plan of measures.

\section{MATERIALS AND METHODS}

This is a qualitative study, evaluating the opinion of hospitalized patients between January-December 2020, in the Pneumophtisiology Hospital of Sibiu.

Working tool: an anonymous questionnaire with preformulated answers, doubled by the interview in elderly patients who had self-completion problems.

Data collection method: collecting all the answers to the questionnaires in a statistical database, by coding and processing the data in tables and graphs, using the Excel Program

The study group consisted of 289 hospitalized patients and the study period was between 01.01.2020 and 31.12. 2020 .

\section{RESULTS AND DISCUSSIONS}

In 2020, 289 questionnaires were applied to patients admitted to Pneumology Departments I and II.

Following the collection and processing of statistical data, we obtained the following results: $49.13 \%$ of patients were hospitalized in the Pneumology Department I and 50.87\% in the Pneumology Department II (figure no.1), having the age group according to figure no. 2 .

Figure no. 1. The distribution of hospitalized patients
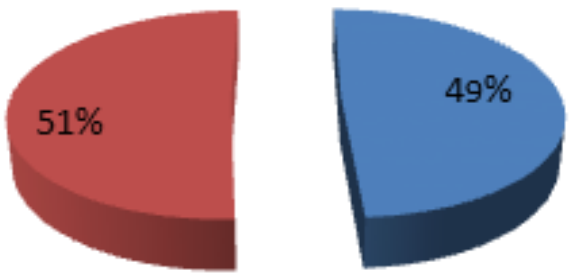

- Pneumology I Pneumology II

${ }^{1}$ Corresponding author: Violeta Frâncu, Aleea Filozofilor, Nr. 3-5, Sibiu, România, E-mail: francuv@ yahoo.com, Phone: +40745 633704 Article received on 19.05.2021 and accepted for publication on 27.08.2021 


\section{PUBLIC HEALTH AND MANAGEMENT}

Regarding the age group of hospitalized patients, on the first place there are patients aged 60-69 years $(33.56 \%)$, followed by patients aged $70-79$ years $(21.45 \%)$ and on third place, there are patients aged $50-59$ years $(19.72 \%)$ and patients aged $70-79(12.5 \%)$.

The least represented are patients in the age group 2029 years $(3.11 \%), 30-39$ years $(5.91 \%), 40-49$ years $(9.68 \%)$ and over 80 years $(6,57 \%)$.

\section{Figure no. 2. Distribution of patients by age group}

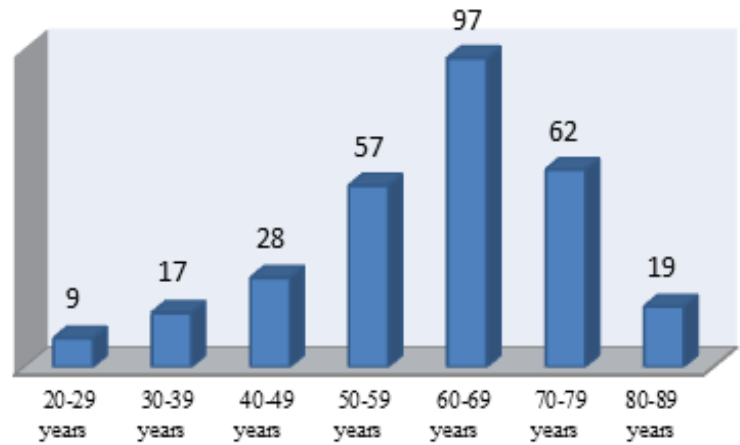

From the point of view of the distribution of patients according to sex, more than half are males, $58.13 \%$ and $41.87 \%$ are females. There also is a preponderance of patients with elementary education $(51.91 \%)$, followed in frequency by those with high school (32.29\%) and those with college, $12.80 \%$.

Most patients arrived at the hospital by ambulance from the Emergency Department (39.81\%), by referral from the family doctor $(34.94 \%)$, or by referral from an outpatient clinic $(20.06 \%)$; the rest of the patient addressed directly the Emergency Room, (20\%).

$100 \%$ of the study patients stated that at admission they received all the information they needed from the attending physician, regarding the disease they were suffering from and the treatment to be instituted.

All patients to whom questionnaires were applied during hospitalization are very satisfied $(78.20 \%)$ and satisfied $(21.80 \%)$ with the way our staff addresses them during hospitalization.

Patients were asked to give ratings regarding the degree of cleanliness, the quality of the linen and the quality of the meals served during the hospitalization. Regarding cleanliness, patients gave only very good $(71.28 \%)$ and good ratings, $(26.98 \%), 1.74 \%$ being dissatisfied. The quality of bed linen is also rated very well and well by patients, with percentages of $62.62 \%$ and $33.91 \% .3 .11 \%$ were dissatisfied. In patients' opinion, the quality of meals served during hospitalization is very good $(66.43 \%)$ and good $(30.44 \%)$ (figures no. 3, 4).

Figure no. 3. Patients' opinion about cleanliness

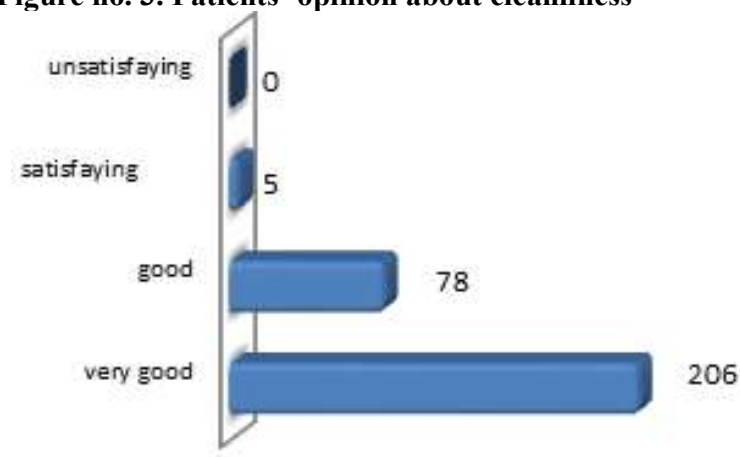

Figure no. 4. The quality of the meals during the hospitalization

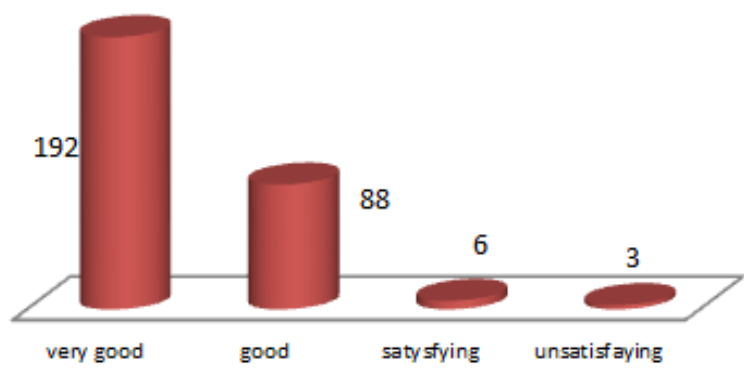

Patients were asked to rate the quality of care during the hospitalization. They gave very good and good grades in a percentage of $85.46 \%$ and $14.18 \%$ for the care provided by doctors, and very good $(83.39 \%)$ and good $(12.2 \%)$ for nurses (figures no. 5,6).

Figure no. 5. Qualifications for doctors

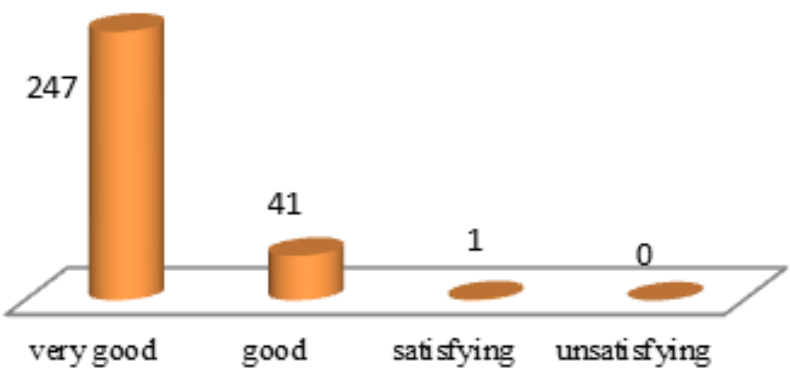

Figure no. 6. Qualifications for nurses

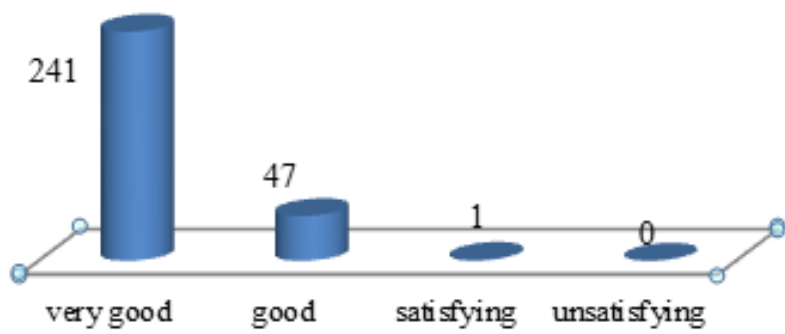

CONCLUSIONS

Between January and December 2020, the opinions of 289 patients were evaluated, regarding the hospital accommodation conditions and the quality of the medical services offered during the hospitalization period.

The working method used was a qualitative one, of opinion, and the working tool was the anonymous questionnaire with pre-formulated answers and self-completion. In situations where patients failed to complete the questionnaire on their own, they were assisted by a nurse or a relative. Patients were randomly selected from both the Pneumology Clinic Section I and the Pneumology Section II, adults. The questionnaires were distributed to the patients by the nurses and returned after completion to the head nurses, who then sent them to the Quality Management Office for processing. The data collected from the questionnaires were coded and processed in the Excel Statistical Program, and the results were represented by graphs and statistical tables. Following the analysis and synthesis of the results obtained, we reached the following conclusions:

Patients who answered the questions came from both geographical areas, mainly from rural areas, are more likely to be males and are mostly between 50-79 years old. 


\section{PUBLIC HEALTH AND MANAGEMENT}

From the point of view of the level of education, most of them have elementary and secondary education.

The results show that patients are satisfied with the way they were communicated health problems, diagnosis and therapy by the attending physician.

Most patients arrived at the hospital for hospitalization by ambulance from the Emergency Room or with a referral from the family doctor, and another part had a referral from an outpatient, or came directly to the hospital's emergency room.

Patients were informed, at admission, about their rights and obligations and also received all the necessary medicines for treatment in the hospital, with a very small exception represented by patients who wanted to buy drugs to support the background treatment, which does not exist. constantly in the hospital's closed-circuit pharmacy (e.g. vitamins for the sick).

Most patients are satisfied with the hospital conditions in the hospital (lighting, heat, quietness), the general cleanliness, the quality of linen and hospital effects, as well as the meals served (food quality and distribution).

Patients were asked to give grades for the quality of medical services. Thus, the overwhelming majority gave "very good" and "good" grades for all medical staff, the best grades being in descending order for doctors, nurses and cleaning staff.

In conclusion, most patients would like to be readmitted to our hospital if they needed in the future.

Recommendations to improve medical care after the assessment of the satisfaction degree of internal patients

1. Continuing the effort of the management team to ensure adequate conditions for hospitalized patients, with the continuous improvement of the hospital's quality standards.

2. Maintaining an appropriate level of hygiene and disinfection at the hospital level, in accordance with the legislation.

3. Continuity of providing the necessary medication to inpatients.

4. Replacing worn bed lines by purchasing new linens.

5. Diversification of patient menus, depending on the season.

6. Adequate communication between healthcare professionals and patients, respecting medical ethics and ensuring a climate of trust and safety for patients.

\section{REFERENCES}

1. Data from the Department of Statistics from the Pneumophtiziology Hospital of Sibiu.

2. Francu V. Management of health services, ULB Sibiu Publishing House ISBN 978-606-1201531-7; 2018. p. 67.

3 . https://anmcs.gov.ro/web/wp-content/uploads/2014/12/5actualizare-MCS1.pdf. Accessed on 1.07.2021.

4. https://www.academia.edu/39505608/managementul_calită ţii_serviciilor_medicale. Accessed on 13.07.2021.

5. Catană Gh. A. Marketingul serviciilor de ocrotire a sănătătii, editura Alma Mater, ClujNapoca; 2009.

6. Ahmad AMK, et al. The Impact of Marketing Mix Strategy on Hospitals Performance Measured by Patient Satisfcation: An Empirical Investigation on Jeddah Private Sector Hospital Senior Managers Perspective, International Journal of Marketing Studies. 2013;5(6):210-227.

7. Aiken LH, et al. Patient safety, satisfaction, and quality of hospital care: cross sectional surveys of nurses and patients in 12 countries in Europe and the United States, British Medical Journal. 2012;344:e1717, DOI 10.1136/bmj.e17171.

8. De Looper M, Damman O, Smets E, Timmermans D, Van Weert J. Adapting Online Patient Decision Aids: Effects of Modality and Narration Style on Patients' Satisfaction, Information Recall and Informed Decision Making, Journal of Health Communication; 2020.

9. Van Weert JC, Van Munster BC, Sanders R, Spijker R, Hooft L, Jansen J. Decision aids to help older people make health decisions: A systematic review and meta-analysis. BMC Medical Informatics and Decision Making. 2016;16(1):45-64. doi:10.1186/s12911-016-0281-8 [Crossref], [PubMed], [Google Scholar]

10. Van Weert JC, van Noort G. Bol N, van Dijk L, Tates K, Jansen J. Tailored information for cancer patients on the Internet: Effects of visual cues and language complexity on information recall and satisfaction. Patient Education and Counseling. 2011;84(3):368-378. doi:10.1016/j.pec.2011.04.006 [Crossref], [PubMed], [Web of Science], [Google Scholar]. 